\title{
EL TRICLINIUM TRICONQUE DEL PALATIUM DE CÓRDOBA
}

\author{
Rafael HIDALGO \\ Universidad de Córdoba
}

\section{Resumen}

En este artículo abordamos el estudio específico de uno de los edificios que conforman el complejo palatino de Cercadilla en Córdoba: el trichorum situado al sur del eje del monumento. Aun cuando se encontró muy arrasado, la información con que contamos en relación con su configuración nos permite proponer su interpretación como triclinium del palacio. Desde un punto de vista formal el edificio está muy relacionado, sobre todo, con el triclinium triconque de Piazza Armerina.

\section{Summary}

In this paper we tacke the specific study of one of the buildings that constitute the «palatial complex» of Cercadilla in Córdoba, Spain: the trichorum situated south of the axis of the monument. Even though the building was found very leveled, the information we have regarding its configuration allows us to interprete it as palace triclinium. From a formal view point, the building is very closely related -above allwith the triclinium of Piazza Amerina.

A partir del exhaustivo conocimiento con que en la actualidad contamos en relación con la planta del palacio imperial de Cercadilla en Córdoba ${ }^{1}$, una de las peculiaridades que más llama la atención respecto al diseño del complejo es la configuración simétrica de la mayor parte de las unidades estructurales que lo conforman. No obstante, la conduplicatio que rige buena parte de la planta del palacio se ve alterada en

\footnotetext{
${ }^{1}$ En lo referente a los aspectos fundamentales del yacimiento de Cercadilla, el complejo arquitectónico allí localizado y su interpretación como palacio tetrárquico vinculado a Maximiliano vid. Hidalgo, 1996a (donde se recoge la bibliografía anterior); en lo concerniente a otra cuestión importante para la interpretación del monumento, como es la posible presencia del esquema palacio-circo en el conjunto cordobés, vid. Hidalgo, 1996 e.p.
} 
algunos casos, en especial en los espacios existentes entre las tres salas de cabecera absidada dispuestas en torno al pórtico en sigma (fig. 1, Edificios A, B y M), en los que el diseño se completa mediante la incorporación de dos construcciones de planta muy diferente en uno y otro caso.

Mientras que en el lateral sur nos encontramos con una sala triconque, en el extremo contrario se diseña un edificio de muy diferente configuración arquitectónica, conformado por una amplia construcción en sigma. Aunque estos dos edificios están relacionados muy directamente, no sólo por su disposición simétrica, sino también por la organización del circuito de acceso e incluso por otros aspectos vinculados a su interpretación y función, en esta ocasión vamos a centrar nuestra atención en el caso concreto del trichorum dispuesto en el extremo sur (fig. 1, Edificio E).

Desgraciadamente el edificio en cuestión corrió la misma suerte que el resto de las construcciones dispuestas en el lugar donde hoy se levanta la estación de ferrocarril de la ciudad, de manera que, además de haber ya desaparecido ${ }^{2}$, había sido arrasado hasta nivel de cimientos antes del inicio de la excavación arqueológica ${ }^{3}$. Por esta razón, la información con que contamos sobre este sector del yacimiento es muy sesgada y parcial, y la configuración planimétrica que hemos podido documentar y que podemos ofrecer, además de incompleta por no conservarse toda la planta del edificio, corresponde exclusivamente a las cimentaciones, sin que podamos contar, en consecuencia, con ninguna evidencia directa respecto a la configuración definitiva que adoptó este sector del palacio una vez replanteados y erigidos los alzados.

Como ocurre en el resto del palacio las cimentaciones siempre apoyan sobre el terreno geológico y, por esta misma razón, la profundidad a la que se excavaban las zanjas se redujo progresivamente en dirección norte, siguiendo el sentido del ascenso natural del terreno. Como consecuencia de este hecho, durante nuestra investigación pudimos constatar que la altura que conservaban estos cimientos se reducía en esa misma dirección, hasta finalmente desaparecer. Por esta razón no conocemos la plan: ta de las estructuras que constituían el extremo norte de este sector -desaparecidas durante el arrasamiento sufrido por el yacimiento-, de manera que ha sido necesario recurrir a la restitución por simetría y al estudio de diversos documentos indirectos para abordar su reconstrucción hipotética.

\footnotetext{
${ }^{2}$ Sobre la problemática relativa al hallazgo y destrucción del yacimiento de Cercadilla, véase Hidalgo, 1996a, $15-22$.

${ }^{3}$ Mientras que, a partir de nuestra hipótesis de restitución del edificio, el nivel al que originalmente se situó su pavimento interno superaría el correspondiente al pórtico en sigma, principal distribuidor del palacio, situado a 121'30 m.s.n.m., los cimientos por nosotros examinados alcanzaban la altura máxima de 118'60 m.s.n.m.
} 
Desde un punto de vista estructural en el conjunto que aquí nos interesa se pueden definir tres elementos interdependientes: un amplio patio de acogimiento, el aula triconque dispuesta en la cabecera del patio y un pequeño edificio de planta centrada (Edificio D), al que se accede a través de un pasillo dispuesto al efecto en el extremo sur del patio distribuidor. De estos tres, dejaremos para otra ocasión el edificio de planta centrada, por responder a una problemática en buena medida diferente, que excede el ámbito estricto, tanto formal como funcional, de la inmediata sala triconque.

Además de la ya mencionada ruptura de la simetría, en relación con la sala triconque llama también la atención su orientación, en tanto que diverge ligeramente de la organización radial asignada al resto de los edificios que, ocupando una posición similar, circundan el pórtico en sigma. De este modo, en lugar de orientarse en función del centro de la gran plaza en sigma, el eje de este edificio se organiza a partir del largo pasillo situado inmediatamente al norte. La razón de esta alteración, a la que volveremos a aludir más abajo, radica en la importancia que, en relación con este grupo de edificios, desempeña el citado pasillo, a través del que se accedía a uno de los espacios más apartados y premeditadamente alejados del conjunto (Edificio L).

En buena medida debido a que sólo contamos con los cimientos, en el diseño en planta, tanto de la sala triconque como del espacio previo, se observan ciertas desviaciones e irregularidades, que en parte habrían quedado paliadas mediante el replanteo de los alzados.

Por otro lado, a partir del análisis de las relaciones físicas de las estructuras conservadas, sabemos que la construcción del trichorum y los espacios que lo preceden fue posterior a la construcción de la sala de cabecera absidada situada inmediatamente al sur (Edificio A), al criptopórtico y, muy probablemente también, a la construcción de al menos parte del largo pasillo situado inmediatamente al norte -en especial en lo referente al muro que delimita al norte el pasillo-, aunque en este caso la comprobación ha sido imposible.

Probablemente la primera estructura que se acometió a la hora de iniciar la construcción de este sector del palacio fue el muro que limita al sur el patio y el trichorum, inicio además del pasillo que conduce al edificio de planta centrada (fig. 7, Estructuras 89 y 94). En el proceso de ejecución de este muro y como primera medida, se excavó una trinchera corrida que abarcaba todo su trazado, no obstante, en un momento anterior incluso al vertido del hormigón para confeccionar los cimientos, se llevó a cabo el replanteo de la estructura y, como consecuencia de ello, en el tramo correspondiente al acceso del pasillo que comunica con el Edificio D, donde lógicamente no debía levantarse el muro, la zanja vuelve a rellenarse con desechos de construcción. 
Del patio distribuidor, que alcanzaría unas dimensiones totales -según nuestra restitución planimétrica- de c. $22^{\prime} 5 \mathrm{~m}$. por $23 \mathrm{~m}$., conocemos sólo los laterales y el extremo sur, mientras que del norte no se ha conservado vestigio alguno. La única información con que contamos en relación con este límite norte, que presumiblemente desempeñó un importante papel en la configuración de estos edificios, es la apreciable en una serie de fotografías correspondientes a las obras de construcción de la nueva estación de ferrocarril de la ciudad, en un momento previo al inicio de nuestra investigación (lám. 3; Hidalgo et alli, 1996, fig. 13 y 33). A ello habría que añadir la aportación proporcionada por la planimetría realizada por técnicos de la Delegación Provincial de Cultura de la Junta de Andalucía en Córdoba, durante el seguimiento arqueológico efectuado antes de que se llevara a cabo el primer arrasamiento del yacimiento y la primera excavación arqueológica (Hidalgo, 1997, fig. 96). A partir del análisis de esta documentación se puede abordar, al menos en líneas generales, la identificación e interpretación de este sector del conjunto.

$\mathrm{El}$ acceso al edificio se realizaría desde el cuerpo rectangular que limita el patio hacia el este -de $8 \mathrm{~m}$. de anchura por $23 \mathrm{~m}$. de longitud-, que probablemente constituiría un vestíbulo, techado mediante una cubierta a dos aguas.

Ya en el patio, la escasa información con que contamos en relación con su configuración procede de las fuentes indirectas ya citadas, con las imprecisiones que ello puede llevar consigo. En un primer momento apuntamos la posibilidad de que en el extremo norte existiese un muro que reprodujese de forma simétrica el cierre sur de este espacio (vid. Hidalgo, 1996b, fig. 1), no obstante, a partir del análisis e interpretación del sistema de accesos al edificio y de la documentación con que contamos en la actualidad, pensamos que probablemente el límite del patio estaría constituido por el propio pasillo de acceso al Edificio L.

En el centro del patio se dispone una serie de estructuras que no han sido objeto de nuestro diagnóstico directo. Su ubicación aproximada nos lleva a plantear que debe tratarse de la cimentación de un pórtico que circundaría por los cuatro lados este espacio abierto (fig. 1) ${ }^{4}$. Ahora bien, queda por discernir cómo pudo configurarse tal pórtico. En la lámina 3 se puede observar en detalle uno de los muros -destruido antes del inicio de nuestra investigación- que, por su ubicación, debe asignarse a esa estructura, en el que se aprecia que sus características constructivas son las comunes

\footnotetext{
${ }^{4}$ Para llevar a cabo la plasmación gráfica y delimitación de este pórtico hemos empleado la ya mencionada planta del seguimiento arqueológico realizado por técnicos de la Delegación de Cultura de la Junta de Andalucía, con carácter previo al primer arrastramiento de la «playa de vías» de la estación de ferrocarril y al inicio de la excavación arqueológica, digitalizada y superpuesta a nuestra cartografía, con el apoyo de distintas fotografías de la zona, previas también a la destrucción de las estructuras.
} 
a todo el palacio: el muro se levanta sobre una cimentación de caementicium realizada en zanja -como demuestra la apariencia irregular de su superficie- que alcanza escasa potencia; sobre el caementicium se dispone la hilada de nivelación de sillares sobre la que, siguiendo la misma secuencia conocida en muchas otras construcciones del palacio, aparece el preceptivo vittatum mixtum, vinculado ya directamente al replanteo y erección de los alzados.

La aplicación de esta técnica nos lleva a considerar más probable que este pórtico estuviera sustentado por pilares de la misma fábrica y no por columnas ${ }^{5}$. Desde el punto de vista estructural, es también muy probable que existiera algún tipo de cerramiento en el ángulo noroeste del pórtico, colaborando en la sujeción de la techumbre, regularizando el espacio y evitando el acceso al perímetro externo del ábside inmediato. No obstante, la ausencia en este caso de testimonio alguno, incluso indirecto, nos ha movido a no abordar ninguna restitución en planta.

De la triconque, al igual que ocurre en los edificios inmediatos, tan sólo hemos podido documentar el caementicium de la cimentación, si bien, en este caso se conservaba también la huella de la hilada de nivelación de sillares, que apoyaba en el caementicium y sobre la que, a su vez, se replantearía y levantaría el alzado de mixtum, siguiendo la secuencia habitual en otras muchas construcciones del palacio. La sala presenta importantes deformaciones en planta que difícilmente pudieron subsanarse con el replanteo de las estructuras en alzado. Ello es debido a que los muros de los laterales adquieren una desviación de más de un grado respecto a los que constituyen la cabecera y acceso.

El acceso al aula se realizaba a través de un vestíbulo absidado gracias a un vano que en cimentación alcanza 2'1 m. de anchura. El vano se dispone ligeramente excéntrico con respecto al eje del edificio, sin embargo, es muy probable que una vez efectuado el replanteo de su alzado alcanzase mayores dimensiones -que a partir de los estudios de modulación se puede estimar en 10 pies- y quedase centrado respecto al eje ${ }^{6}$.

\footnotetext{
${ }^{5}$ En la mencionada lámina 3 y en el tramo central del paramento parece observarse una alteración en la secuencia constructiva: se elimina el basamento de sillares y, además, se deja un hueco en reserva que. eso sí, a partir exclusivamente de la observación de la fotografía, podría interpretarse como un vano. No obstante, la consecuencia que se deriva de esta apreciación. es decir, que el mencionado pórtico estaría realmente conformado por un muro corrido en el que tan sólo se abrirían algunos vanos para permitir la comunicación del pasillo con el patio central, nos lleva a cuestionar que realmente se trate de un vano, pues lo cierto es que este tipo de solución no es la más frecuente en las construcciones de las características de la que aquí nos ocupa.

${ }^{6}$ Es muy probable que el vestíbulo se encontrara abierto y porticado en su conexión con el peristilo, como ocurre en otras construcciones similares a las que haremos mención más abajo.
} 
Por su parte, el interior de la sala alcanza $16^{\prime} 3 \mathrm{~m}$. de longitud frente a $14^{\prime} 1 \mathrm{~m}$. de anchura, mientras que los ábsides alcanzan en torno a 6'7 m. de diámetro. El espacio interno del edificio aparece compartimentado por una serie de pequeños muros dispuestos de forma ligeramente asimétrica respecto a los ábsides, construidos, en parte, tras la erección de los muros maestros del edificio y, en parte -ángulo sudeste-, a la vez. En lo que se refiere a la interpretación de estas estructuras, una primera posibilidad sería que se tratase de la cimentación de una hipotética columnata, que sustentaría la bóveda hemisférica que habría constituido la cubierta del edificio, de forma que, siempre que los apoyos de las columnas estuvieran asegurados, no debía importar demasiado la perfecta distribución simétrica de estos muretes de cimentación respecto al resto de las estructuras emergentes. No obstante, lo cierto es que esta posibilidad cuenta con importantes problemas estructurales y, además, a partir de su propia configuración formal, lo más lógico es suponer que el edificio contara con una cubierta adintelada (fig. 6) ${ }^{7}$.

Una segunda posibilidad que se podría apuntar es que estos muros internos correspondieran a una segunda fase, en la que se habría producido la transformación del edificio, si bien en función de la información de que disponemos esta hipótesis cuenta con demasiados problemas para ser aceptada ${ }^{8}$.

\footnotetext{
${ }^{7}$ La sección del trichorum que ofrecemos en la mencionada figura 6 no tiene la vocación de convertirse en una propuesta de reconstrucción del edificio, sino sencillamente ilustrar nuestra interpretación. Para ello y habida cuenta de la escasa información con que contamos en Cercadilla, nos ha sido de gran utilidad las reconstrucciones realizadas para el pórtico ovoide y el peristilo principal de Piazza Armerina por M. Medri (Carandini, Ricci y Vos, 1982, 384-392).

La secuencia ascendente que proponemos para los pavimentos -de los que obviamente no contamos con ningún vestigio- está basada en las documentada en los dos pórticos ya citados de Piazza Armerina (vid. Settis, 1975, passim) y, sobre todo, en la secuencia ceremonial ascendente documentada en otros sectores del palacio cordobés. La solución que planteamos para la superposición de la fachada del trichorum, el vestíbulo biabsidado previo y el pórtico, está muy influenciada por la correspondiente a la basílica-vestíbulo-peristilo de Piazza Armerina y sería, a fin de cuentas, muy similar a la aplicada al nártex en las iglesias cristianas (vid. infra). En lo concerniente a los alzados, los problemas inherentes a la propia planta nos han movido a no formular ninguna propuesta de modulación y a aplicar una ratio similar a la presumible en otros edificios del conjunto. Por su parte, la anchura de los muros ha sido corregida y adaptada a la documentada en los alzados de otros edificios similares del palacio.
}

${ }^{8}$ Se podría pensar que en esta hipotética segunda fase los ábsides originales habrían quedado en desuso, con lo que, en realidad nos encontraríamos con una nueva sala triconque, con un espacio central más reducido y tres nuevas exedras, esta vez rectangulares, en cabecera y laterales. Por su parte, el pórtico absidado se habría mantenido en el mismo sitio, mientras que para el cierre de las nuevas exedras se habría usado, en el caso de las situadas en cabecera y lateral norte el tramo correspondiente de la estructura original, y en la dispuesta al sur se habría construido un nuevo muro de cabecera.

El resultado final de esta hipotética transformación no sería otro que una sala muy similar a otras bien conocidas, en especial el triclinium de la villa de Diocleciano en Split. No obstante, aunque esta hipótesis es tremendamente sugestiva, lo cierto es que cuenta con algunos problemas que dificultan su aceptación. Ante todo, las hipotéticas nuevas exedras alcanzan dimensiones muy reducidas que complican el posible uso y 
Quizás estas estructuras estuvieran sencillamente vinculadas a la contención de los empujes norte-sur a nivel de cimientos, sin contar con desarrollo en alzado, como sabemos que muy probablemente ocurría en otros edificios del complejo.

\section{Trazado arquitectónico y Modulación}

A partir del análisis global de la planta del palacio y de cada uno de los elementos que lo componen, hemos propugnado la aplicación de un módulo de cinco pies, o sea, un passus, como unidad maestra según la cual pensamos se llevó a cabo la organización de las distintas estructuras y espacios del conjunto (vid. Hidalgo, 1996a, 6972). Ahora bien, en los edificios que han llegado hasta nosotros en peor estado, la comprobación de la aplicación del módulo propuesto se complica, ya que de ellos sólo se conservan los cimientos y en ningún caso contamos con vestigios de las alineaciones de los alzados, sobre los que verdaderamente se ajustaría la modulación.

A pesar de ello, hemos considerado oportuno proceder a superponer las tramas modulares sobre sus plantas, nunca con el propósito de identificar la modulación concreta, sino con el fin de comprobar si sobre las cimentaciones conservadas cabría la posibilidad de llevar a cabo el replanteo según la trama de cinco pies $\mathrm{y}$, en el caso concreto del edificio objeto de este estudio, comprobar y ratificar además su vinculación con el pasillo que permitía el acceso al inmediato Edificio L.

En la sala que aquí nos ocupa la situación se complica debido a un incuestionable -e importante- error de construcción, consistente en la desviación del muro que constituye su cabecera $1^{\prime} 92^{\circ}$ respecto a los muros laterales y, junto a éste, el resto de los muros transversales del edificio. Esta circunstancia impide completamente que la malla modular pueda coincidir en su superposición con todas las estructuras del edificio -ya sean las cimentaciones conservadas o los alzados perdidos-. Sin embargo, si procedemos a la superposición de nuestra parrilla en función de la alineación de cada uno de los dos muros que conforman los laterales del aula (fig. 2a y b), podemos

aprovechamiento de su interior: miden tan sólo de 2 a $3 \mathrm{~m}$. de fondo y $4 \mathrm{~m}$. de ancho (en Split alcanzan c. 7 m. de lado). La homogeneidad de la técnica constructiva aplicada en estas estructuras con respecto al resto del monumento y la excepcionalidad de esta técnica en la ciudad, ligada tan sólo a la fundación del palacio, hacen difícil pensar que correspondan a otra fase o momento posterior. Por otro lado, aunque en la mayor parte de los casos estos muros de compartimentación interna se entregan a los muros perimetrales, en el lateral sudeste (Estructuras 103 y 391) -y a pesar del alto grado de arrasamiento sufrido por el edificioparece que las estructuras internas traban con los muros maestros del límite sur, ábside y del vestíbulo de acceso (Estructuras 93, 94 y 380), correspondiendo pues a un mismo momento. Por último, como más abajo se podrá comprobar, a pesar de las notables desviaciones patentes en la materialización del edificio, la modulación presumible para su diseño teórico coincide también en lo referente a las estructuras dispuestas en el interior de la sala, lo que igualmente apuntaría a su concepción como parte del diseño original del edificio en una única fase. 
comprobar que se producen bastantes coincidencias en las alineaciones, tanto de los muros que definen el vestíbulo de acceso, como de los que configuran la propia sala, los ábsides de los laterales e incluso los muros del interior, lo que constituye evidencia suficiente para confirmar la aplicación, también en este edificio, de la modulación propuesta en otras construcciones del palacio.

Algo similar ocurre en el amplio espacio abierto que distribuía el paso hacia el trichorum y hacia el edificio de planta centrada situado inmediatamente al sur. Aquí vuelve a observarse a simple vista una importante desviación de las estructuras, evidente consecuencia de un error en el trazado del diseño durante su materialización y ajuste al inmediato pórtico semicircular.

A pesar de ese error y alineando la parrilla modular en función del muro que delimita al sur el edificio (Estructura 89), cuyo papel predominante en el trazado de las construcciones de esta zona es incuestionable, se pueden observar importantes detalles (fig. 3).

Especialmente cabe resaltar la coincidencia y ajuste de las principales alineaciones de la trama modular de esta zona respecto al pasillo situado inmediatamente al norte, que comunica con el Edificio L, lo que viene a ratificar la vinculación formal y funcional existente entre ambos, de modo que entre estos dos edificios no sólo se produciría la coincidencia en la orientación de los ejes -como anteriormente apuntábamos-, sino que incluso también se produce la coincidencia en la disposición de la traza modular.

Del mismo modo, la proporción del espacio parece convergir en esta misma intención: el sector central, o sea, el pórtico, se concibe como un espacio cuadrangular con una clara proporción 1:1 (15 Módulos x $15 \mathrm{M}$ ), mientras que el pasillo del Edificio $\mathrm{L}$ y el vestíbulo situado al este del pórtico parecen coincidir en este intento de mantener la proporción general 1:1, ya que ambos alcanzan $6 \mathrm{M}$ de anchura interna, proporcionando al espacio una magnitud total de $22 \mathrm{M}$ × $22 \mathrm{M}$.

Los evidentes desajustes que se observan en la superposición de la trama modular a partir de las estructuras orientadas de norte a sur (fig. 4), deja bien claro que fue en el replanteo y construcción de estas estructuras donde se produjo el error patente en el edificio, muy probablemente fomentado por su posición tangencial respecto al pórtico en sigma o incluso por los imperativos derivados del propio proceso constructivo ${ }^{9}$.

\footnotetext{
${ }^{9}$ Éste es el caso de las termas, construidas tras la ejecución de los edificios inmediatos, lo que obligó a adaptar y «comprimir» el diseño teórico al espacio final real existente (Hidalgo, 1996a, 73-139). Desde una perspectiva eştructural este proceso no carece de lógica, de manera que en un primer momento se ejecutarían los edificios directamente conectados con el pórtico en sigma y en un segundo momento los dispuestos en los espacios intermedios.
} 
A los efectos de lo que aquí nos interesa, de la aplicación de la trama modular cabe destacar especialmente el hecho de ratificar la vinculación de este edificio al pasillo inmediato, tal y como apuntaba la propia disposición de los ejes de uno y otro. Esta vinculación constituye un argumento importante de cara a la interpretación de otro aspecto de relevancia, como es el propio sistema de acceso al edificio. De este modo, la vinculación tanto del trichorum como de los espacios anejos al pasillo inmediato, habría estado motivada porque el acceso a su interior se habría llevado a cabo de forma indirecta a través del pasillo en cuestión, siguiendo un esquema idéntico al documentado en el extremo opuesto del palacio (fig. 1).

\section{Interpretación del Diseño}

Dentro del evidente gusto por el espacio absidado, patente en el diseño general del palacio, se ha de inscribir sin duda la sala triconque que aquí nos ocupa.

De todos es sabido que la planta triconque responde a un esquema que experimenta un importante desarrollo en la arquitectura romana. Su origen arranca de época altoimperial -a partir de precedentes más que probablemente helenísticos-, si bien será ya durante el Bajo Imperio cuando alcance su cenit, adquiriendo gran profusión. El esquema en cuestión no cuenta con un uso preestablecido e inmutable, sino que a lo largo del amplio marco temporal en el que está en uso se irá adaptando a distintas funciones, alcanzando también un amplio desarrollo geográfico en sus distintas aplicaciones, desde mausoleo ${ }^{10}$ a ninfeo ${ }^{11}$, sin olvidar los edificios termales ${ }^{12}$.

A partir del s. IV la arquitectura cristiana adoptará también este esquema, adaptado a sus necesidades, de manera que ahora adquiere un importante desarrollo aplicado a la

${ }^{10}$ Como mausoleo lo encontramos, por ejemplo, en la tumba de Claudia Antonia Sabina en Sardis (Siria) del 191 d.C. (Butler, 1922, 170), en el mausoleo de Pecs (Hungría), en el hipogeo de Iarhai (Palmira) o también en la necrópolis de Isola Sacra (Zovatto, 1965, 10), si bien, lo cierto es que este uso no es muy frecuente.

${ }^{11}$ La propia configuración formal del esquema responde a una concepción arquitectónica adecuada también para el diseño de los ninfeos, como es el caso de la fuente Peirene en Corinto, en la imagen que adquirió con la remodelación llevada a cabo por Herodes Atico, y el ninfeo situado al sur del área de los quattro tempieti en Ostia (vid. Grossman, 1992, 189). La datación de los dos ejemplos en el s. II d.C. permite situarlos en una posición privilegiada en el desarrollo del modelo.

${ }^{12}$ En los edificios termales, vinculado también al agua, se aplica preferentemente en la construcción de los caldaria, en los que la planta triconque permite la incorporación de tres alvei, uno en cada ábside, si bien en estos edificios tampoco constituye un esquema desarrollado con profusión. De los espacios triconques asociados a edificios termales cabe destacar los casos de las termas de Thuburbo Majus y Feriana en el Norte de África (Ben Abed-Ben Kader et alii, 1985, 1-7, lám. 1-4 y Zovatto, 1965, 17) y, muy especialmente, en lo concerniente a su aplicación a termas imperiales, los casos de las termas constantinianas de Augusta Treverorum (Nielsen, 1990, 72) y las de Trajano y Diocleciano en Roma (Yegül, 1992, 142-146 y 163-169). 
configuración de martyria ${ }^{13}$ y, sobre todo, iglesias ${ }^{14}$, en las que se hace muy común especialmente entre los siglos V y VI, con especial profusión en el norte de Africa.

No obstante, la aplicación que más nos interesa aquí es la concerniente a los edificios residenciales o representativos, en concreto casas, villas o palacios. En esta aplicación son muchos los edificios que cuentan con una sala triconque entre sus dependencias principales.

Desde un punto de vista funcional se ha intentado identificar en esta estancia la sala del trono propia de los palacios imperiales. De esta forma y según la teoría elaborada desde la "architettura di potenza", especialmente con las contribuciones de E. Dyggve (1941) y S. Bettini (1955), a partir de la concepción del ábside como

${ }^{13}$ Como martyrium lo encontramos, por ejemplo, en Concordia Saggitaria (Forlati, 1960), con frecuencia en el Norte de África, donde se encuentran los de Damous el Karita, Ksar Hellal o Bir Ftoucha (Túnez) (Duval y Cintas, 1976, 900-903), y en otro caso en Corinto (Milburn, 1988, 76). Con el esquema algo evolucionado destaca la memoria de Tepljush (Drinš) (Cambi, 1984) o la de Santa Sinforosa en la vía Tiburtina (Testini, 1980, 239-240). La planta triconque se puede aplicar también a salas anejas a las iglesias, especialmente baptisterios, como es el caso de la basílica eufrasiana de Porec (Krautheimer, 1981, 325 y 346), la basilica de Santa Eufemia de Grado (con los ábsides de la triconque muy poco desarrollados), Didyma (Zovato, $1965,14)$ y la basílica oriental de Apollonia, donde el baptisterio posiblemente fue concebido en origen como martyrium (Stucchi, 1975, 371-375). Vinculado también a la arquitectura cristiana lo encontramos ya en el s. IV aplicado a mausoleos, como ocurre en los cementerios de San Calixto en Roma, en el Mausoleo IX junto a la iglesia n. 6 de Bin-bir-Kiliseh o en la capilla funeraria de la Trinidad de Lérins (Testini, 1980, 90 y $657-660$ ).

${ }^{14}$ En su profusa aplicación al diseño de las iglesias podemos citar, entre los edificios más representativos, la iglesia de S. Félix del Cimitile-Nola (Campania), la de Akrini (Grecia) (Pallas, 1977, 88), la de Teurnia (Pillinger, 1989), la Trinidad de Vercelli, la basílica de S. Pancrati de Cava d'Ispica (Testini, 1980, 687 y 693); la iglesia Este de Caricin Grad (Duval, 1984, 445-448) y las de Topolica (Bar), Doljani (Tilograd), Cim (Mostar), Sutivan (Brac), Bilice (Šibenik), Tepljuh (Drniš) y Pridaga (Zadar) en el Este Adriático (Cambi, 1984); las iglesias egipcias de Dendera (Effenberger, 1975, 103-104), Dayr Amba Bakhum (Akhmim), Dair Anba Bishuy (Suhag) y Dayr Anba Shinuda (Suhag) (Beyer, 1925, 19; Walters, 1974 y Grossman, 1992) o las de Tebessa Khalia o Kherbet bou Adouffen también en Africa (Argelia) (Duval y Cintas, 1976, passim), las de Ras Siaga (Monte Nebo) o San Juan Bautista de Jerusalén en Palestina, etc.

La catedral de Hermópolis Magna (Ashmunein, Egipto) (Effenberger, 1975, 82; Milburn, 1988, 144-146) constituye un buen ejemplo de triconque a partir del desarrollo del transepto, quizás como resultado de la fusión del transepto en cruz con el presbiterio trilobulado, muy común en Egipto en el s. V (Krautheimer, 1981, 134). Un caso similar, con los ábsides laterales muy evolucionados, es el de la Basílica III (llamada cruciforme o bizantina) de Iunca (Bizacena) (Duval, 1973, 241-254), las basílicas griegas de Dodona y Paramythia y, dentro de la misma concepción de triconque a partir de transepto absidado, la basílica de la Natividad en Belén (Testini, 1980, 658).

En la Península Ibérica cabe destacar São Frutuoso de Montelios, con un original esquema en el que los ábsides de planta de herradura conforman un esquema cruciforme, San Martín de Dumio (Braga) (Oliveira, 1995) y, muy especialmente, la aplicación del esquema en un momento ya muy avanzado en los casos de Terrasa (Moro, 1987), con un tratamiento muy cercano a los ejemplos más clásicos, y San Cebrián de Mazote. 
elemento glorificante se considera el aula triconque espacio especialmente privilegiado para la representación del ceremonial imperial, como sala del trono. Según esta propuesta el ábside central desempeñaría el cometido de acoger al emperador, mientras que los ábsides laterales desempeñarían funciones de acompañamiento y albergarían a los herederos del trono $\mathrm{u}$ otros miembros de la familia imperial particularmente cercanos al emperador, que le acompañarían durante las ceremonias, o, en última instancia, a altos funcionarios ${ }^{15}$.

A partir del supuesto modelo que habrían constituido estas triconques imperiales, la aplicación de tal planta a edificios privados habría asumido también el cometido de conformar salas de audiencia. Sin embargo, lo cierto es que, según la información con que contamos en la actualidad en relación con la configuración formal de los palacios imperiales, no existe una casuística suficiente que permita afirmar que el trichorum constituye el modelo preferentemente elegido a la hora de constituir las salas de audiencia imperial.

Ante esta situación, comúnmente se acepta que la sala triconque en general desempeña la función de triclinium, como resultado de la adaptación de las formas arquitectónicas a las nuevas costumbres sociales del Bajo Imperio, en concreto a la difusión de los nuevos lechos en sigma, los stibadia. La única función representativa que desde un punto de vista global se puede asignar a las salas triconques, es aquella relacionada con los triclinia y, eso sí, con el destacado papel que en el Bajo Imperio desempeña el convivium, constituyendo un marco arquitectónico idóneo para la celebración de los banquetes. Aunque no es una emulación de la sala del trono imperial, imprime a los edificios en los que se inscribe cierto carácter distintivo, quizás como indicio de status, constituyendo lo que Lavin (1962, passim) califica como "emphasized triclinium", en una muy acertada postura conciliadora, en la que propugnando el carácter de triclinium para estas salas no les niega cierto papel representativo.

Un edificio que destaca especialmente en el origen y desarrollo de este esquema es la sala con tres ábsides de Villa Adriana. No obstante, el indudable modelo que constituye esta sala, cuenta con una serie de peculiaridades que en cierta medida la diferencian y distancian de lo que será el desarrollo del esquema triconque en época posterior, sobre todo en lo concerniente a su evolución en la arquitectura doméstica

\footnotetext{
${ }^{15}$ De esta forma se establece una extrapolación directa de otro concepto esencial de la architettura di potenza como es el tribunal -con su ejemplo paradigmático en el pórtico de acceso a los apartamentos imperiales de la villa de Diocleciano en Split-, dividido también en tres espacios claramente jerarquizados, con un gran arco central y dos menores laterales, en los que se desarrollaría el ceremonial áulico de una forma similar a la propugnada para el trichorum. Este esquema sería, según esta misma teoría, el que aparece representado en el missorium de Teodosio.
} 
bajoimperial. De hecho, en el caso de Villa Adriana nos encontramos con una sala rectangular central que en realidad es en sí misma el espacio representativo, ya que en este caso los ábsides perimetrales no se conciben como espacio de acogimiento -donde pudieran disponerse los stibadia-, sino que en realidad constituyen pequeños jardines circundados por pórticos. La diferencia es aún mayor si tenemos en cuenta que, como ha demostrado Kähler (1950), el edificio originalmente se concibió con un único ábside en la cabecera y sería en un momento posterior cuando se le añadieron los dos ábsides de los laterales, adoptando ya su imagen definitiva.

Una vez visto este complejo precedente, es posible enlazar, remontándonos en el tiempo, con el que podría ser el auténtico modelo de este esquema, el triclinium de la Domus Flavia, constituido por un aula rectangular con ábside en la cabecera, flanqueada a ambos lados por dos exedras conformadas por sendos ninfeos circundados por pórticos. No obstante, desde un punto de vista estructural en este caso también se han de advertir importantes diferencias con la configuración estricta del trichorum (vid. Lavin, 1962, n. 31).

Sea como fuere, a partir de la importante influencia que pudieron ejercer estos edifícios u otros similares, es ya en época bajoimperial, especialmente entre finales del s. III y principios del s. V, cuando el trichorum adquiere su definición precisa como parte de la "arquitectura doméstica", imponiéndose además en la configuración de los triclinia y adquiriendo un importante desarrollo en las villae y domus de las provincias occidentales ${ }^{16}$, incluida la Península Ibérica ${ }^{17}$ (fig. 8).

\footnotetext{
${ }^{16}$ Aulas triconques las encontramos, entre otros muchos lugares, en la Casa del Carro de Venus y en la Casa de los Prótomos de Thuburbo Majus, las dos en África, como el aula que acogía los famosos mosaicos con representación arquitectónica de Tabarka; en dos destacados ejemplos como son la villa de Patti Marina (Voza, 1982, fig. I) y Piazza Armerina, a la que posteriormente aludiremos con especial atención, o la de Desenzano junto al lago Garda (Scagliarini, 1992), en el Norte de Italia; en la domus romana de Largo argentina, a partir de la interesante -aunque incompleta- configuración transmitida por Lanciani (Guidobaldi, 1980, 175-181), y en la casa situada al N. de la iglesia episcopal de Perge (Ellis, 1983, 210).

${ }^{17}$ De los ejemplos hispanos cabe citar, en especial, la villa de Los Quintanares (Rioseco, Soria), Las Mezquitillas (Écija), la del Camino Viejo de las Sepulturas (Balazote, Albacete) (Gorges, 1979 y Femández Castro, 1982, 207-208) o Torre Águila, originalmente concebida como aula tetraconque que más tarde se convierte en triconque (Rodríguez Martín, 1988 y 1995). En la villa de Almenara de Adaja (Valladolid) y en la villa de Materno en Carranque (Toledo) (Fernández-Galiano et alii, 1991), las exedras de las triconques adquieren un desarrollo tan reducido que les proporciona a ambas un aspecto muy peculiar. Por su parte, en la interesante villa de Rabaçal (Pessoa, 1991 y 1995) aparece en dos casos, mostrando, a fin de cuentas, las posibilidades multifuncionales con que cuenta el modelo. En este establecimiento merece especial mención el triclinium triconque en el que, aunque adquiere importantes dimensiones, como ocurría en los primeros precedentes el espacio a ocupar se centra en el rectángulo central, mientras que de los ábsides perimetrales -desproporcionados en sus dimensiones en planta- el de la cabecera constituía un ninfeo y los laterales servirían de apoyo al servicio o al sistema de iluminación (Pessoa, 1995, 486).
} 
A ello habría que añadir, en una hipotética categoría superior a la de los establecimientos domésticos - a veces cuestionable-, otros edificios en los que se ha defendido su adscripción a importantes personajes. Este es el caso del "palacio de Teodorico" en Rávena (Ghirardini, 1918), en el que el trichorum se dispone junto al aula basilical, que sin duda constituye el principal espacio representativo del edificio. Aparece también en el conocido como "palacio del gobernador" de Afrodisias (Erim, 1975), en donde es la cella trichora la sala que preside el peristilo, desplazando de ese lugar preeminente al aula basilical. Una vez más la encontramos en el palacio del dux ripae de Dura Europos (Downey, 1993), donde constituye el coronamiento del pórticomirador sobre el Eufrates, que inevitablemente recuerda al pórtico de la villa de retiro de Diocleciano; en el "palacio de los caballos" de Cartago, interpretado como residencia del gobernador, sede de una corporación o sencillamente residencia de un aristócrata (vid. Lavin, 1962, 6 y 26; Picard, 1952 y 1964); en el palacio de Bosra, del que se conoce poco más que la trichora y el peristilo al que estaba asociada (Lavin, $1962,10)$, etc. ${ }^{18}$, alcanzando un amplio desarrollo tanto geográfico como cronológico ${ }^{19}$.

En el caso de la villa de Diocleciano en Split, tan recurrente en el estudio del palacio cordobés, lo cierto es que este edificio no cuenta con un esquema triconque en sentido estricto, pero basta una rápida observación del triclinium del palacio para comprobar que realmente constituye una variación de la planta triconque, con un planteamiento que enriquece la configuración habitual del esquema tripartito, siguiendo la tendencia creativa común tanto en la arquitectura tetrárquica como en la propia villa de retiro del fundador de la Tetrarquía.

Ahora bien, en el caso que aquí nos ocupa, la sala triconque del palacio de Cercadilla, es incuestionable que su configuración formal presenta una similitud muy

\footnotetext{
${ }^{18}$ También aparece en la casa del triconchos de Ptolemais, que según Goodchild (1964) podría haber constituido el palacio del $d u x$ antes de que su officium fuera trasladado a Apollonia, a mediados del s. V o poco después; en el «palacio de Byrsa» (Lezine, 1968, 177-179, fig. 6) y en el praetorium de Gortina (Johannowski, 1960, 991 y Sanders, 1982, 79-80), reconstruido por el gobernador de Creta en el s. IV, con una pequeña «sala de recepción» triconque de morfología muy sencilla y mal conocida. Vinculado ya a la arquitectura cristiana cabe mencionar la sala de recepción del palacio episcopal de Side, fechada en el s. V o s. VI (Mansel, 1978, 267-269).
}

${ }^{19}$ Ligado ya a la arquitectura omeya cabe destacar la interesante triconque de Mšatta, que se ha querido interpretar muy vinculada a la «architettura di potenza» (Bettini, 1955) o, con el esquema muy evolucionado y puede que incluso concebido como tetraconque, en el palacio de Qasr ibn Wardân (Butler y Prentice, 1919-1920, 26-46), quizás propiedad de un príncipe árabe que ayudó a Justiniano en su enfrentamiento contra los persas (Ellis, 1983, 240). No se debe olvidar tampoco la trascendencia y pervivencia del modelo triconque en la arquitectura imperial del medioevo -como reflejo, a fin de cuentas, del fuerte empuje proporcionado por la arquitectura bajoimperial-, gracias a su presencia en el Gran Palacio de Teófilo en Constantinopla o incluso en el palacio del Papa León III en el Laterano y en el de Carlomagno en Ingelheim (vid. Lavin, 1962, passim), este último concebido, como el palacio de Córdoba, a partir de una gran exedra. 
especial con el triclinium triconque de Piazza Armerina (fig. 5). En lo que respecta a las salas en sí mismas, el modelo aplicado en uno y otro caso es especialmente análogo (fig. 8) y sus dimensiones son muy similares ${ }^{20}$. No obstante, si bien la planta de ambas es muy semejante, lo más interesante de su comparación es su evidente similitud en lo que respecta a la configuración y disposición de las salas respecto al resto del edificio: tanto una como otra se disponen en comunicación directa con un pórtico previo, al que presiden, recordando el esquema adoptado en las casas y villas en lo concerniente a la ubicación del triclinium en relación con el peristilo.

Es también importante resaltar que en ambos casos el pórtico en el que se inscriben las triconques no es el principal del establecimiento, sino uno secundario. El pórtico principal se ubica en un lugar privilegiado y presidido en uno y otro ejemplo por el aula basilical destinada a las funciones representativas, mientras que las aulas triconques se disponen en sendos pórticos dispuestos en uno de los laterales, en una zona premeditadamente diferenciada y separada del espacio representativo. Esta misma peculiaridad viene a ratificar que la función que desempeñarían estas salas no estaría en relación directa con el principal aparato representativo, sino que, siguiendo la tendencia anteriormente expuesta, sería la de triclinium, en el que los ábsides estarían destinados a albergar los stibadia. Por su parte, el espacio central que delimitan los ábsides sería usado por los sirvientes encargados de servir comida y vino a los comensales, llevar cuencos de agua para que pudieran lavarse las manos y cuidar las lámparas durante las celebraciones. Asimismo, este ambiente central proporcionaría un espacio adecuado para amenizar los banquetes mediante actuaciones de actores, músicos y danzarines (Rossiter, 1991, 203).

Llegados a este punto, sólo un aspecto nos queda por tratar en relación con la configuración del trichorum de Cercadilla. Nos referimos, en concreto, a la original configuración que adquiere el pórtico o vestíbulo situado ante el aula, gracias a la incorporación de un ábside en cada uno de los extremos. Este esquema, que será más tarde adoptado por la arquitectura cristiana ${ }^{21}$, constituye una solución vanguardista

${ }^{20}$ En el aula cordobesa el espacio central de la sala alcanza mayores dimensiones que en Piazza Armerina, mientras que en la sala siciliana las dimensiones de los ábsides son ligeramente superiores a las de los ábsides de la triconque de Cercadilla. No obstante, las dimensiones totales que alcanzan una y otra son muy similares, superiores a las concernientes al resto de las salas que se adaptan al mismo modelo arquitectónico (fig. 8). Además, en ambos casos se reproduce la misma configuración del esquema, esto es, la concepción del trichorum a partir de una clara sala cuadrangular en torno a la que se adosan los ábsides, reproducido en los mismos términos tan sólo en la villa de Rabaçal, aunque en este caso con ciertas peculiaridades que la diferencian claramente de Cercadilla y Piazza Armerina (vid. supra nota 17).

${ }^{21}$ Este es el caso, por ejemplo, de la basílica central de Apollonia (Stucchi, 1975, 369), la de Kampanopetra (Salinis, Chipre) (Pallas, 1977, 293), la catedral de Afrodisias (Erim, 1975) o la iglesia de Dendera (Egipto), donde el nártex biabsidado forma parte de una iglesia de cabecera triconque (Effenberguer, 1975, 103-104); 
que cuenta con algunos elementos de comparación en la propia arquitectura tetrárquica. Este es el caso del edificio milanés de vía Brisa (Mirabella, 1984, 79; Arslan, 1982, 200 y Heger, 1985-86), que formaba parte del palacio imperial de la capital milanesa, y, sobre todo, del octógono de Tesalónica, en el que el vestíbulo biabsidado adquiere considerables proporciones en relación con la sala y, por ende, cierta autonomía funcional, convirtiéndose en precedente de otros edificios posteriores en los que se aplica una solución similar. Entre ellos, el pabellón de los Horti Liciniani -en la configuración que adopta en el s. IV-, o, en especial, el mal llamado "palacio de Lausos", donde el triclinium -en este caso polilobulado-, está precedido por un vestíbulo biabsidado que conecta con un pequeño pórtico en sigma ${ }^{22}$.

A partir de lo hasta ahora visto se puede comprobar que, sin menoscabo de la innegable originalidad del diseño global del palacio, los elementos que lo componen, tratados de forma aislada, forman parte, tanto en lo referente a los modelos elegidos como en su tratamiento, de la tradición arquitectónica de la que indudablemente tuvo que partir el arquitecto responsable del diseño del conjunto. No obstante, se inscriben en esta tradición con un talante creativo que deja su impronta en la propia evolución de los modelos y en el tratamiento aplicado en su materialización, y que poco más tarde tendrá su reflejo en la arquitectura cristiana.

Como ya se ha podido comprobar, éste es el caso del triclinium triconque del palacio, no sólo en lo que se refiere a la adopción y definición del modelo, sino también en

o de otras iglesias de planta no basilical como San Vital de Rávena, San Lorenzo de Milán o, sobre todo, San Gereón de Colonia, donde la relación entre el pórtico biabsidado y la iglesia es más cercana al caso que aquí nos ocupa, con una solución que, salvando las distancias, puede relacionarse con la arquitectura civil y con modelos muy próximos a la arquitectura imperial. También aparece en edificios anejos a las iglesias, como es el caso de la cella trichora de la basílica eufrasiana de Porec, donde el pórtico biabsidado alcanza considerables proporciones en relación con la propia sala, o en la iglesia de S. Leónidas de Corinto (vid. Krautheimer, 1981, 325; 346 y 154-157). Asociado a edificios de planta centrada destaca especialmente el mausoleo imperial de la dinastía Honoria en S. Pedro de Roma, Santa Constanza y el mausoleo imperial, en este caso octogonal, de S. Aquilino, junto a San Lorenzo de Milán, en el que, eso sí, el atrio biabsidado no formó parte de la configuración original del edificio.

${ }^{22}$ Otro pórtico biabsidado de similares características es, a fin de cuentas, el ambulacrum situado ante el aula «basilical» de Piazza Armerina, según un modelo que, conformando el lateral del peristilo situado ante la sala de recepción, lo encontramos en el Palacio de las Columnas de Ptolemais (Pesce, 1950), que juega un destacado papel en el desarrollo del modelo. También aparece ante el triclinium triconque de la villa de Materno (Carranque, Toledo) -además de en el «edificio de planta basilical» del mismo establecimiento-; con unas dimensiones más modestas, ante el aula absidada de la domus emeritense de la calle Morería (Alba, 1997, fig. 6), y conformando un vestíbulo de amplias proporciones, ante la sala de recepción del «Palacio Abovedado» de Efeso (Ellis, 1983, 197-198, fig. 43). Ya como vestíbulo adaptado a las dimensiones del aula que preside -con el exterior de los ábsides ajustados a la alineación del edificio-, lo encontramos en el aula de Junio Basso, donde se aplica una solución muy similar a la que, vinculada ya a la arquitectura cristiana, aparece en el martyrium de Marialba (Hauschild, 1972). 
su imbricación con el resto del conjunto, en concreto en lo concerniente a su disposición respecto al aula de recepción, siguiendo un esquema que, como ya se ha dicho, nos acerca especialmente a la villa de Piazza Armerina y a otros edificios que, con unas connotaciones más modestas y en momentos más avanzados ${ }^{23}$, o bien recibieron el influjo de estos grandes conjuntos, o bien bebieron de fuentes coincidentes.

\section{BIBLIOGRAFÍA}

ALBA, M. (1997): "Ocupación diacrónica del área arqueológica de Morería (Mérida)", en: P. Mateos et alii (coord.): Mérida. Excavaciones arqueológica 1994-1995, Mérida, 285-315.

ARSLAN, E. (1982): "Urbanistica di Milano Romana. Dall'insediamento Insubre alla capitale dell'Impero", ANRW II, 21.1, 179-210.

BEN ABED-BEN KHADER, A. (1985): Thuburbo Majus. Les mosaïques du quartier central de Djemila (Cuicul). Études d'antiquites africaines. Aix-en-Provence.

BEK, L. (1983): "Questions Convivales. The Idea of the Triclinium and the Staging of Convivial Ceremony from Rome to Byzantium", Analecta Romana Istituti Danici XII, 81-107.

BETTINI, S. (1955): "Il castello di Mschattà in Transgiordania nell'ambito dell' "arte di potenza" tardoantica". Anthemon. Scritti di Archeologia e di Antichità Classiche in Onore di Carlo Anti, Florencia, 321-366.

BEYER, H. W. (1925): Der Syrische kirchenbau, Berlín.

BLANCHETं, A. (1909): "Les origines antiques du plan tréflé”, Bulletin Monumental $73,450 \mathrm{ss}$.

BUTLER, C. (1922): Sardis, I, 1. Leyden.

BUTLER, H. y PRENTICE, H. (1919-1920): Publications of the Princeton Archaeological Expedition to Siria 1904-1905 and 1909, Division II, Architecture, Brill Leiden.

CAMBI, N. (1984): "Triconch churches on the eastern Adriatic", X Congres. Int. d'Archeologia Chretienne, II, Vaticano, 45-54.

\footnotetext{
${ }^{23}$ Éste es el caso de aquellos edificios, ya sean palacios, casas o villas, en los que la gran sala basilical constituye el principal espacio del establecimiento, mientras que el trichorum realiza funciones de acompañamiento, como ocurre, entre otros ejemplos, en el «palacio de Teodorico» en Rávena o en el palacio del dux de Dura Europos.
} 
CARANDINI, A; RICI, A. y VOS, M. DE (1982): Filosofiana: La villa di Piazza Armerina. Imagine de un aristocratico romano al tempo di Costantino. Palermo.

DEICHMANN, F. W. (1950): s.v. "Cella trichora", Reallexikon für Antike und Christentum, Stuttgart, II, col. 944 ss.

DOWNEY, S. B. (1993): "The Palace of the Dux Ripae at Dura-Europos and «Palatial» Architecture of late Antiquity", Eius Virtutis Studiosi: Classical and Post-Classical Studies in Memory of Frank Edward Brown (1908-1988), Hannover, 183-200.

DUVAL, N. (1973): Les églises africaines a deux absides, II, Inventaire des monuments, interpretation. BEFAR 218 bis, París.

DUVAL, N. (1984): "L'architecture religieuse de Tsaritchin Grad dans le cadre de l'Illyricum oriental au VIe siècle", Villes et peuplement dans l'Illyricum protobizantin, Actes du colloque organisé par l'École française de Rome (Roma, 12-14 de mayo de 1984), 399-481.

DUVAL, N y CIN'TAS, J. (1976): "Le martyrium de Cincari et les martyria triconques et tétraconques en Afrique", MEFR 88, 853-927.

EBERT, F. (1864): s.v. “Trichorum”, RE, Stuttgartt, vol. VII A i, col. 91.

DYGGVE, E. (1941): Ravennatum palatium sacrum. La basilica ipetrale per ceremonie. Studi sull'architetura dei palazzi della tarda antichità. Copenhague.

EFFENBERGER, A. (1975): Koptische kunst Ägypten in spätantiker, byzantinischer und frühislamischer Zeit, Wien.

ELLIS, S. P. (1983): An archaeological Study of Urban Domestic Housing in the Mediterranean A.D. 400-700.Oxford.

ERIM, K. (1975): "Aphrodisias in Caria: the 1973 campaign", Türk Arkeoloji Dergisi XXII.2, 73-92.

FERNANDEZ CASTRO, M. C. (1982): Villas romanas en España. Madrid.

FORLATI, B. (1960). "Il Sepulcreto palecristiano di Concordia Sagittaria", Cah. Arch. 11, 251-255.

FERNÁNDEZ GALIANO, D.; PATÓN, B. Y BATALLA, C. M. (1991): "Mosaicos de la villa de Carranque: un programa iconográfico", VI Coloquio Internacional sobre mosaico antiguo (Palencia-Mérida, Octubre de 1990), Guadalajara, 317-326.

GHIRARDINI, G. (1918): “Gli scavi del Palazzo di Teodorico à Ravenna”, Monumenti Antichi (Accademia dei Lincei) XXIV, 1916, 737-838. 
GODOY, C. (1995): Arqueología y liturgia. Iglesias Hispánicas (siglos IV al VIII). Barcelona.

GOODCHILD, R.G. (1960): Kyrene und Apollonia. Zurich.

GOODCHILD, R. (1964): "Fortificazioni e palazzi in Tripolitania e Cirenaica, CCARB, 225-250.

GORGES, J. G. (1979): Les villas hispano-romaines. Inventaire et problématique archéologique. París.

GROSSMANN, P. (1992): "The triconchoi in Early Christian Churches of Egypt and their origines in the architecture of Classical Rome", Roma e l'Egitto nell'architettura classica (Atti del I Congresso Internazionale italo-egiziano), Roma, 182-190.

GUIDOBALDI, F. (1980): "L'edilizia abitativa unifamiliare nella roma tardoantica", en: Giardina, A. (ed.): Società romana e Impero Tardoantico, II; Roma. Politica, economia e paesaggio urbano. Roma-Bari, 165-235.

HAUSCHILD, TH. (1972): "Undersuchungen in der Martyrerkirche von Marialba (Prov. Leon) und im Mausoleum von Las Vegas de Pueblanueva (Prov. Toledo)", Actas del VIII Cong. Int. de Arqueología Cristiana, Barcelona, 327-332.

HEGER, A. G. (1985-86): "L'area archeologica di via Brisa e il problema del Palatium imperiale di Milano", Sibrium 18, 137-159.

HIDALGO, R. (1996a): Espacio público y espacio privado en el conjunto palatino de Cercadilla (Córdoba): el aula central y las termas. Sevilla.

HIDALGO, R. (1996b): "Análisis arquitectónico del complejo monumental de Cercadilla (Córdoba)", en: LEÓN, P. (ed.) Colonia Patricia Corduba una reflexión arqueológica, Sevilla, 235-248.

HFDALGO, R. (1996 e.p.): "La incorporación del esquema palacio-circo a la imagen de la Córdoba bajoimperial", en: Simposio Internacional de Epigrafía. Ciudades privilegiadas en el Occidente romano: naturaleza y evolución, organización jurídica y modelos urbanos. Sevilla.

HIDALGO, R. (1997): El complejo palatino de Cercadilla en Córdoba. Tesis doctoral inédita.

HIDALGO, R; ALARCON, F; FUERTES, Mª; GONZÁLEZ, M. y MORENO, M. (1996): El criptopórtico de Cercadilla: arquitectura y secuencia estratigráfica, Sevilla.

JOHANNOWSKI, W. (1960): s. v. "Gortina”, EAA III, Roma, 987-993.

KÄHLER, H. (1950): Hadrian und seine villa bei Tivoli. Berlín. 
KRAUTHEIMER, R. (1981): Arquitectura paleocristiana y bizantina. Madrid.

LAVIN, I. (1962): "The House of the Lord: Aspects of the Role of Palace triclinia in the architecture of Late Antiquity in the Early Middle Age", Art Bulletin 44, 1-27.

LEZINE, A. A. (1968): Carthago-Utique, París.

MANSEL, A. (1978): Side, Türk Tarih Kurumu.

MILBURN, R. (1988): Early Christian Art and Architecture, Aldershot.

MIRABELLA, M. (1984): Milano romana. Milán.

MORO, A. (1987): "Revisió i interpretació de les superposicions basilicals de la seu episcopal d'Egara", Terme 2, 42-54.

NIELSEN, I. (1990): Thermae et Balnea. The Architecture and Cultural History of Roman Publics Baths. Aarhus.

OLIVEIRA, L. F. (1995): "A igreja sueva de Dume (Braga)", IV Reunió d'Arqueologia Cristiana Hispànica, Barcelona, 415-427.

PALLAS, D. (1977): Les monuments paléochrétiens de Grèce découverts de 1959 à 1973, Roma.

PESCE, G. (1950): Il palazzo delle Colonne in Tolemaide di Cirenaica, Roma.

PESSOA, M. (1991): "Villa romaine de Rabaçal , Penela (Coimbra, Portugal): réalités et perspectives", Conimbriga XXX, 109-119.

PESSOA, M. (1995): "Villa romana do Rabaçal. Penela (Coimbra-Portugal) - Notas para o estudo da arquitectura e mosaicos", IV Reunió d'Arqueologia Cristiana Hispànica, Barcelona, 471-491.

PILLINGER, R. (1989): "Neue Ausgrabungen und befunde frühchristlicher denkmaler in osterreich (1974-1986)", Actes du XI Congres International d'Archéologie Chrétienne, Roma.

RODRÍGUEZ MARTÍN, F. G. (1988): "La villa romana de la dehesa de Torre Águila en Barbaño-Montijo (Badajoz)”, Extremadura Arqueológica I, 201-219.

RODRÍGUEZ MARTIN, F. G. (1995): "La villa romana de Torre Águila (BarbañoMontijo, Badajoz)", JRA 8, 312-316.

ROSSITER, J. (1991): "Convivium and Villa in Late Antiquity", en: Slater, W. J. (ed.): Dinning in a classical Context. Michigan, 199-214.

SANDERS, I. F. (1982): Roman Crete. An archaeological survey and gazetteer of late Hellenistic, Roman and early Bizantine Crete, Londres. 
SCAGLIARINI, D. (1992): Villa romana Desenzano. Roma.

SETTIS, S. (1975): “Per l'interpretazione di Piazza Armerina", MEFRA 87, 873-994.

STUCCHI, S. (1975): Architettura Cirenaica, Roma.

TESTINI, P. (1980): Archeologia cristiana. Bari.

VOZA, G. (1982): "Le ville romane del Tellaro e di Patti in Sicilia e il problema dei rapporti con l'Africa", 150-Jahr-Feier Deutsch. Arch. Inst. Rom., 202-209.

WALTERS, C. C. (1974): Monastic archaeology in Egypt. Warminster.

YEGÜL, F.K. (1992): Baths and bathing in classical antiquity. N.Y.

ZOVATTO, P. L. (1965): “Origine e significato della Trichora-Martyrium, l'essempio di Concordia", Palladio 15, 7-34. 


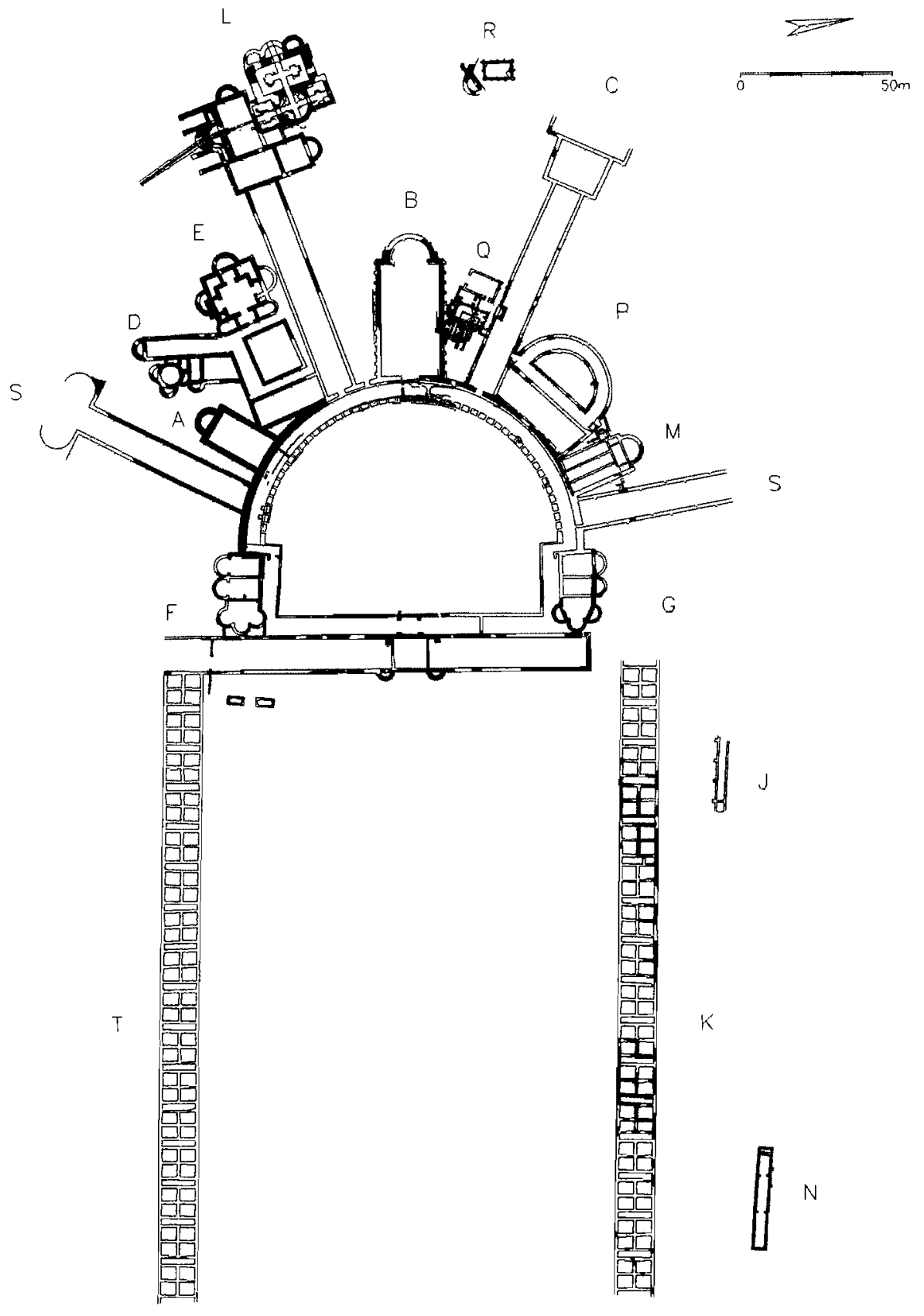

Fig. 1: Planta general del palatium de Córdoba. 
A)
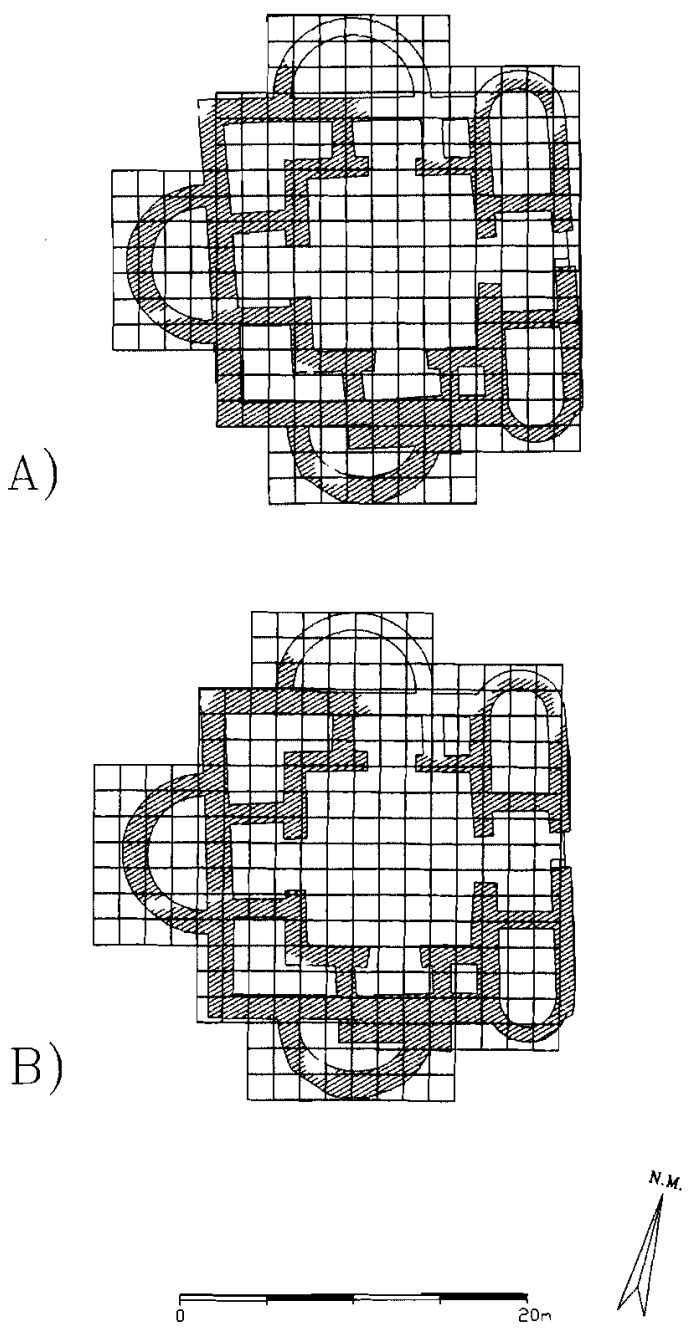

Fig. 2: Aplicación de la trama modular ajustada desde el ángulo sudeste de la sala (a) y desde el ángulo nordeste (b). 


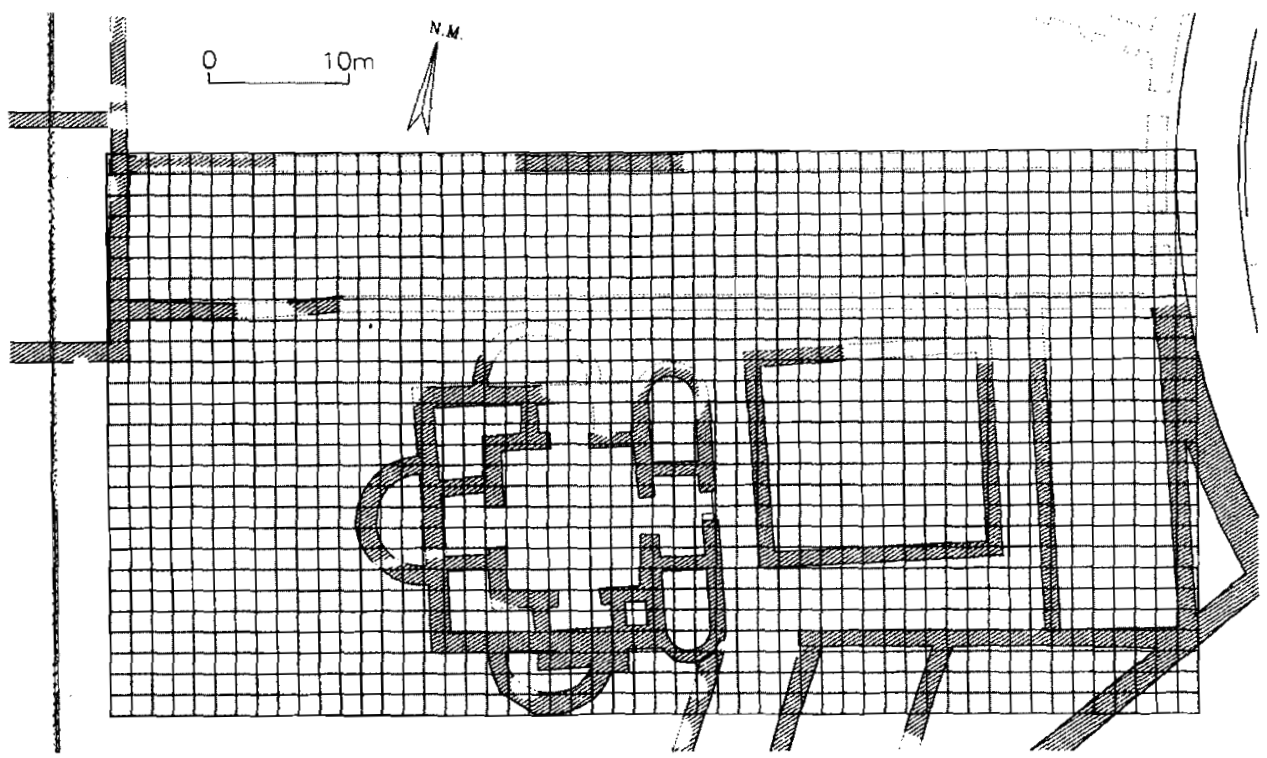

Fig. 3: Aplicación de la trama modular al trichorum y al entorno (pasillo Edificio L), a partir de las Estructuras 89 y 94.

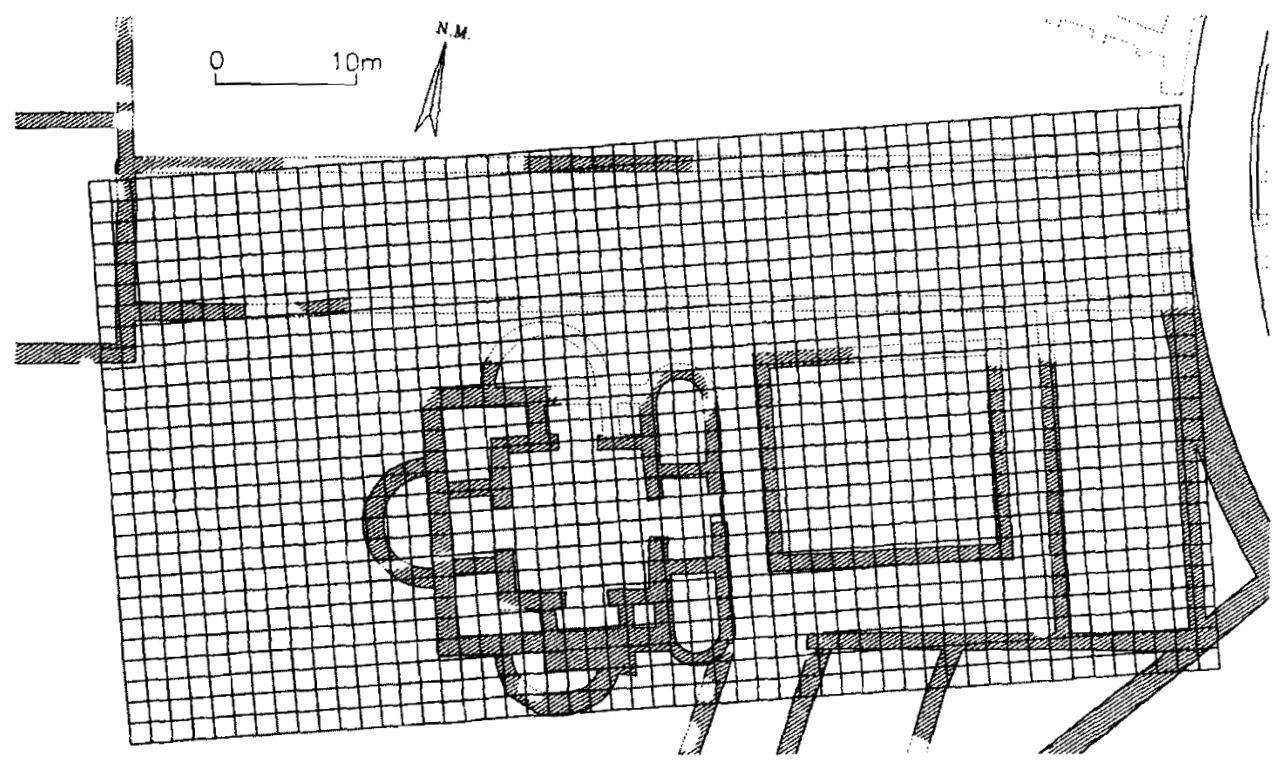

Fig. 4: Aplicación de la trama modular al trichorum y al entorno (pasillo Edificio L), a partir de la cabecera del trichorum (Estructura 95). 

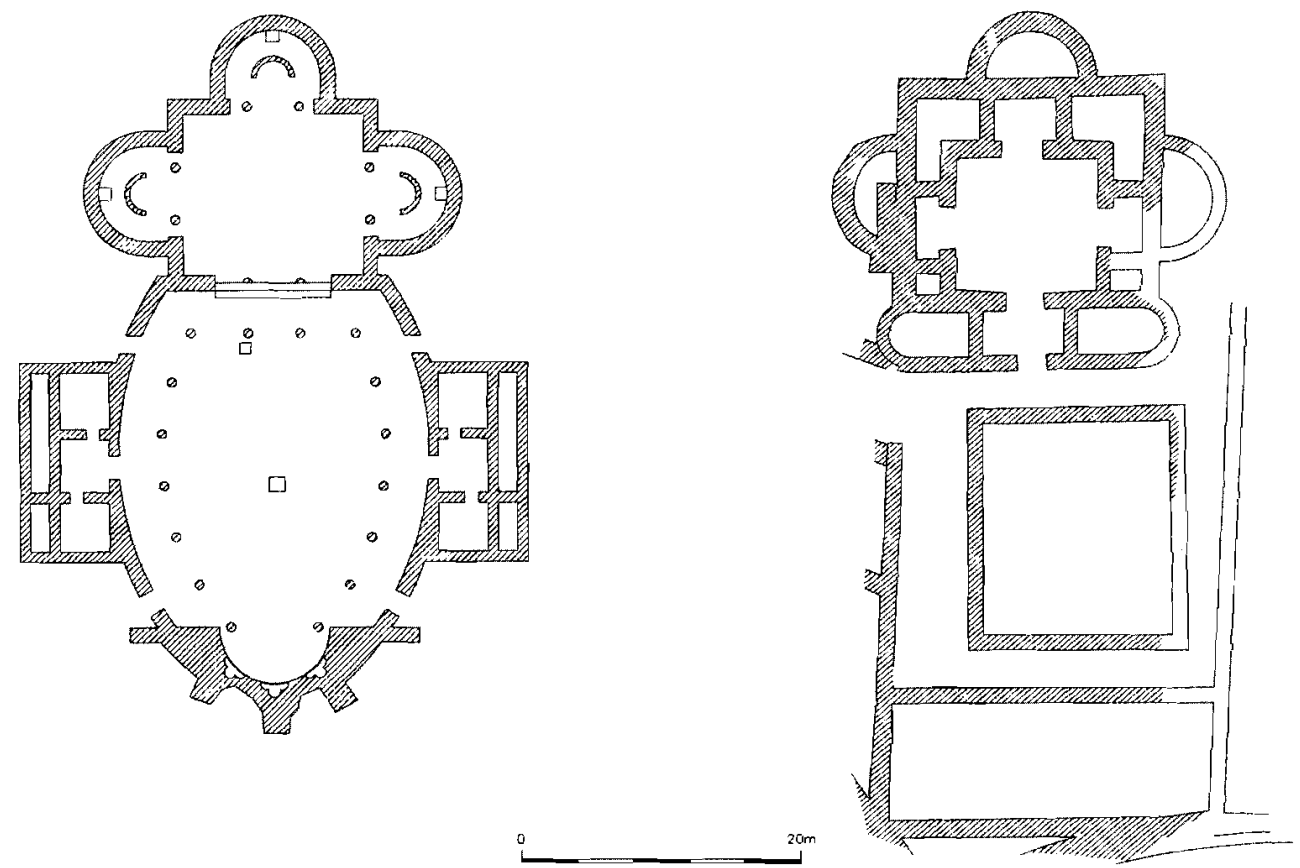

Fig. 5: Comparación del trichorum de Córdoba con el de Piazza Armerina.

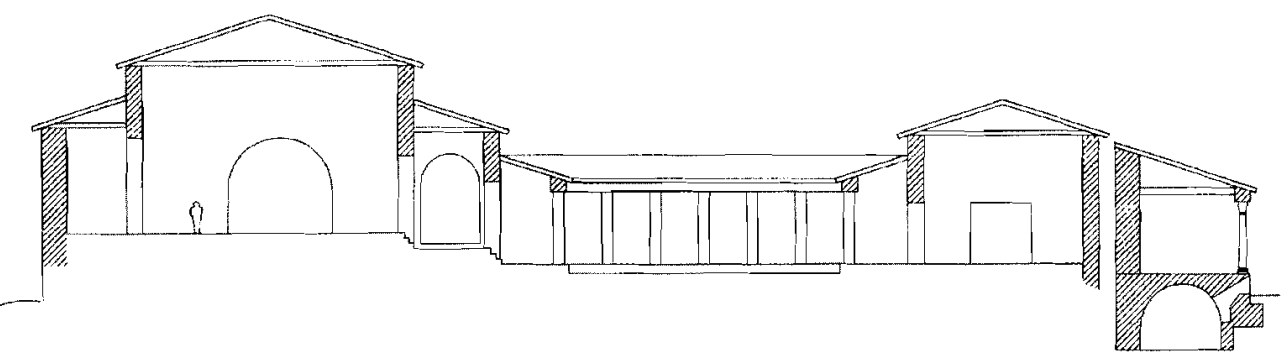

Fig. 6: Sección ideal del trichorum de Córdoba y del espacio previo. 
A)

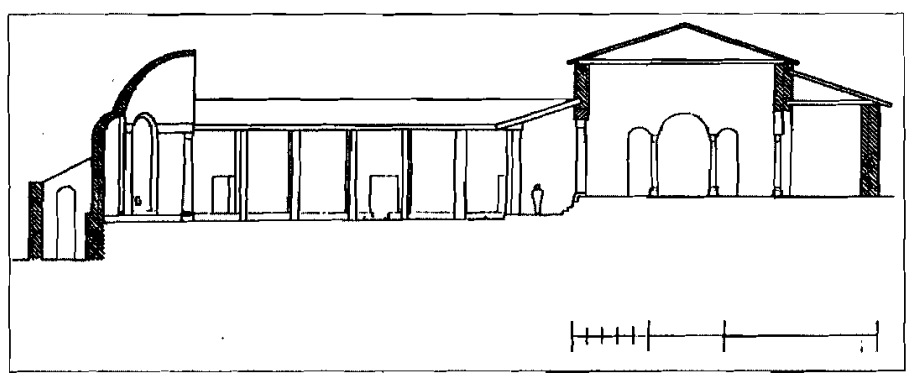

B)

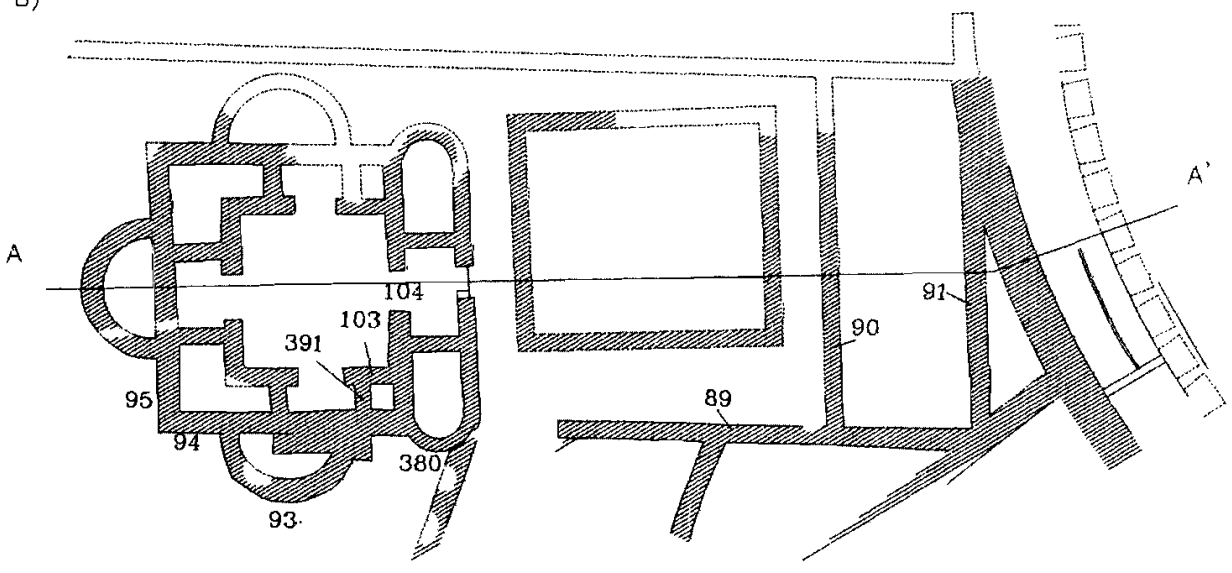

ㄴ. $10 \mathrm{~m}$

Fig. 7: A) Sección del trichorum de Piazza Armerina; B) ubicación sobre la planta de la sección de la lámina anterior y denominación de estructuras. 

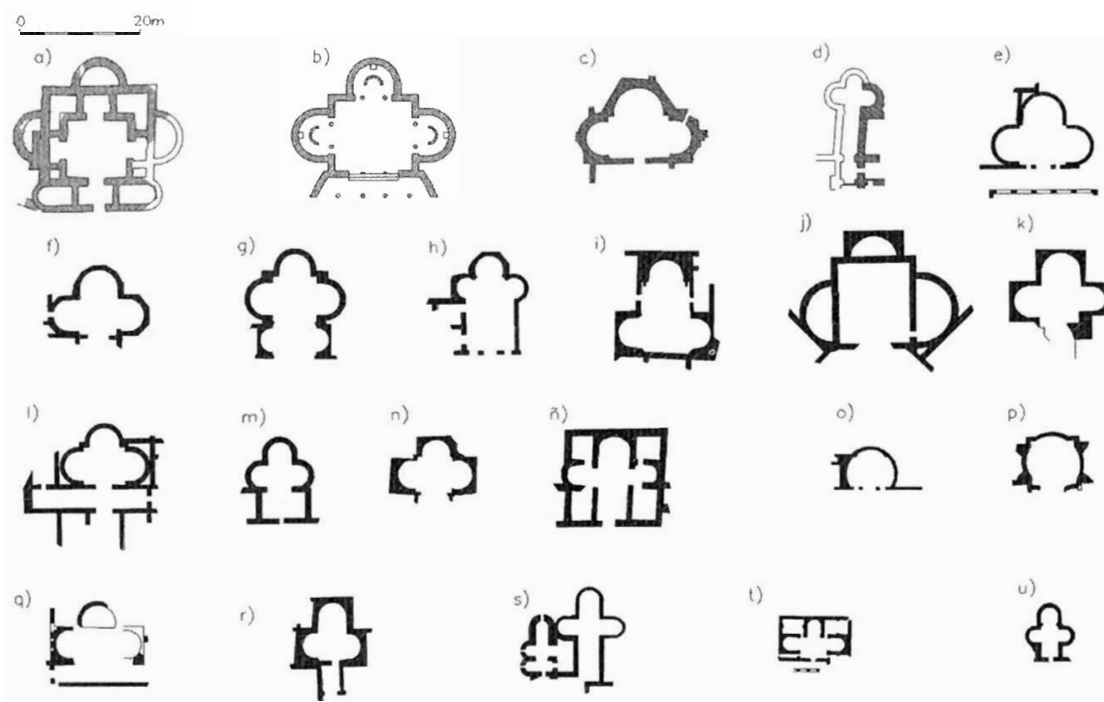

Fig. 8: Planta comparativa aulas triconques: a) Cercadilla; b) Piazza Armerina; c) "Palacio del gobernador" de Afrodisias; d) Palacio del dux de Dura Europos; e) Villa de Patti Marina; $f$ " "Palacio de Teodorico" en Rávena; g) Villa de Desenzano del Garda; $h$ ) Casa del Carro de Venus (Thuburbo Majus); i) Casa del Triconchos, Ptolemais; j) y k) Villa de Rabaçal; I) Villa de Las Mezquitillas, Ecija; m) Villa de Los Quintanares; $n$ ) Villa de Torre Aguila; ñ) Villa de Torre de Palma; 0 ) Villa de Almenara de Adaja; p) Villa de Carranque; q) Cartago, schola; r) Villa de Thuburbo Majus; s) Villa de El-Alia, villa; t) Palacio de Bosra; u) Villa del Camino Viejo de las Sepulturas, Balazote.

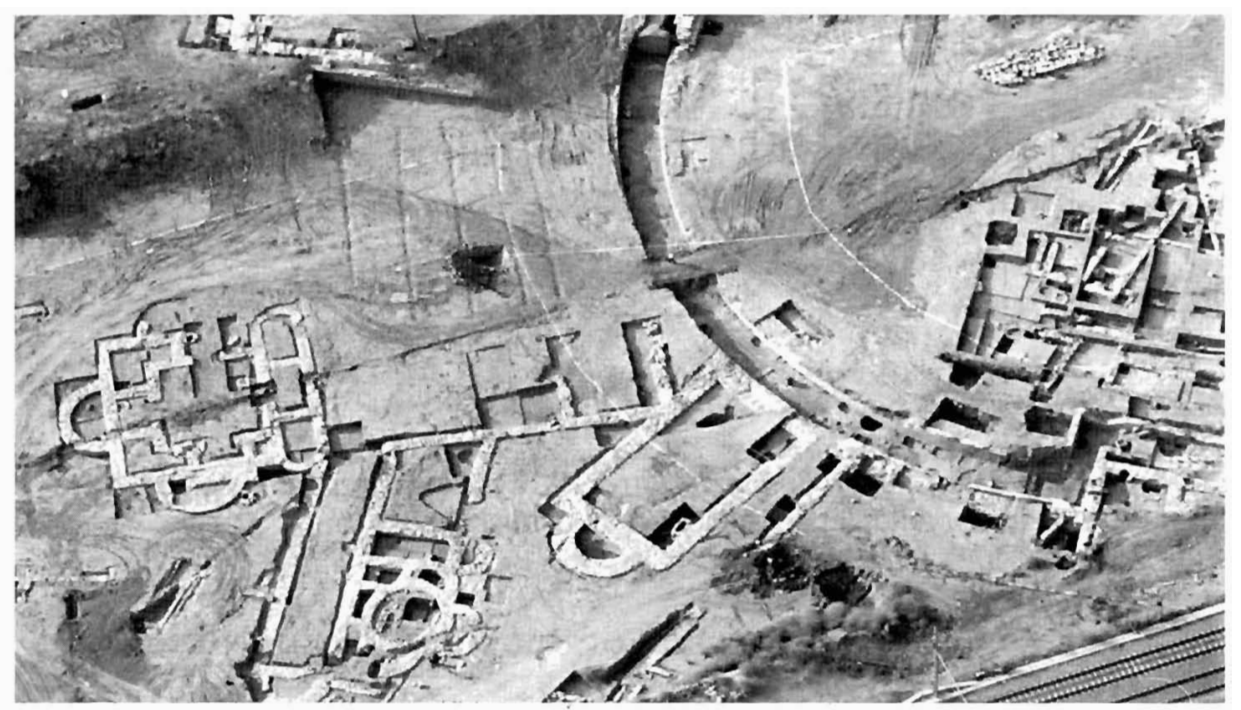

Lám. 1: Panorámica del aula triconque de Cercadilla y espacios anejos. 


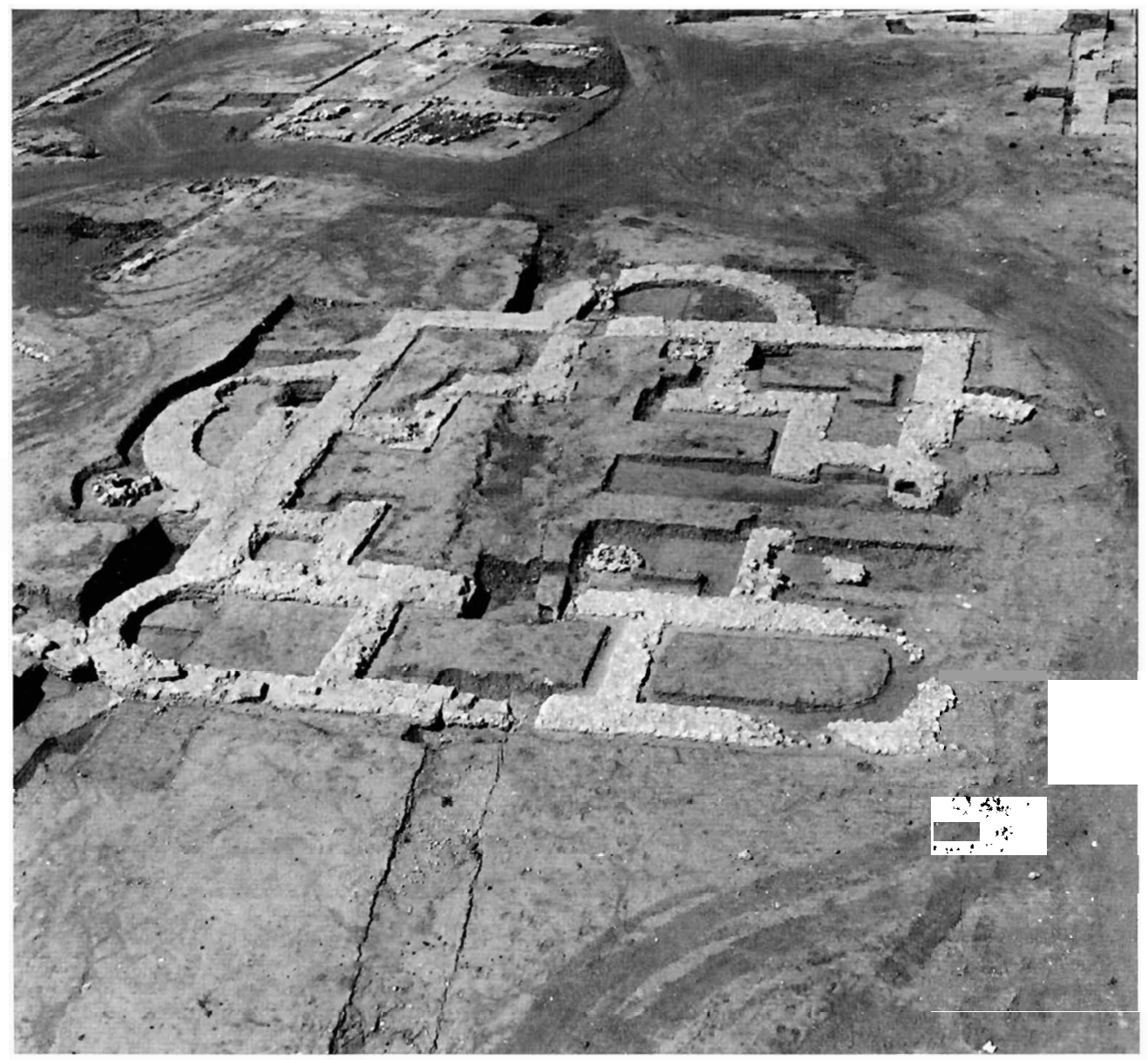

Lám. 2: Detalle del trichorum. 


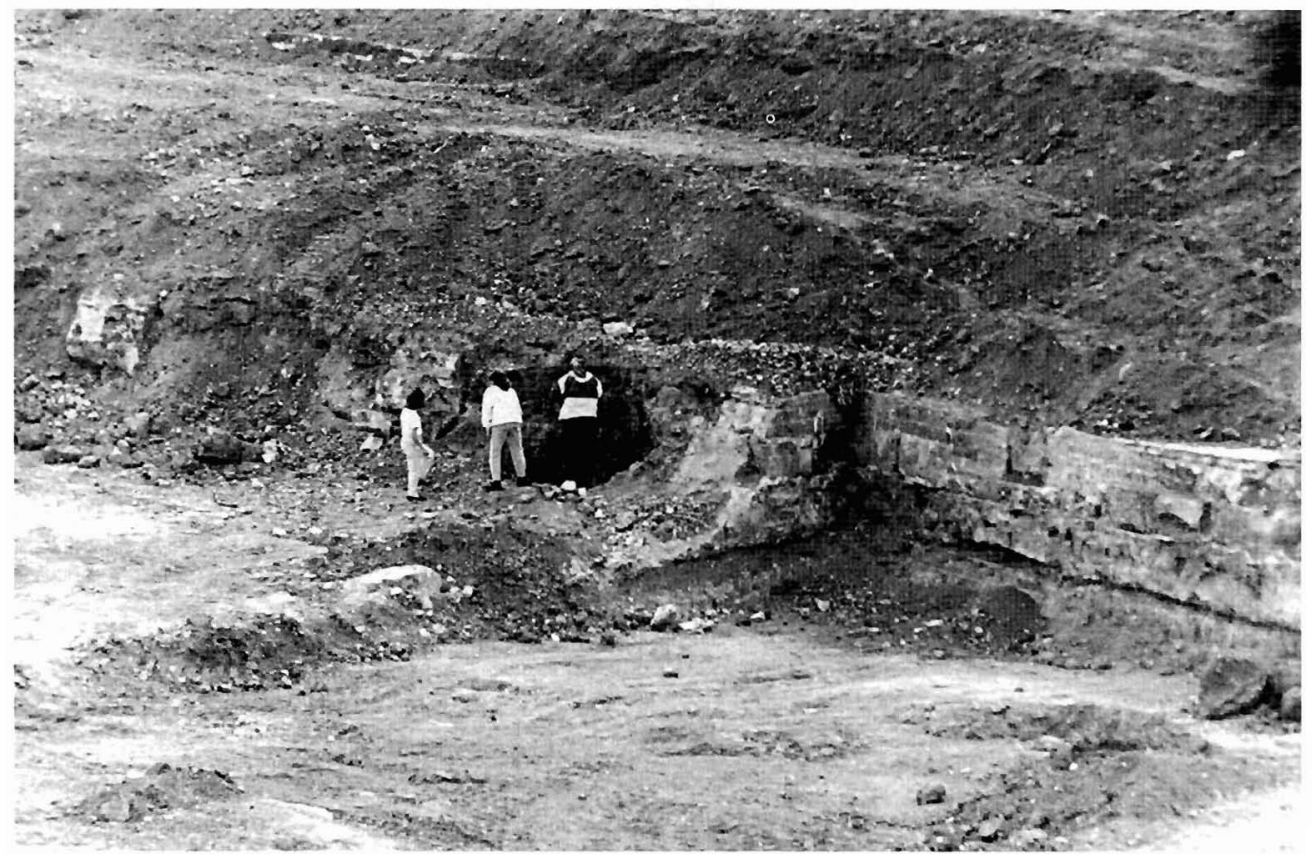

Lám. 3: Detalle de las estructuras del pórtico situado ante el trichorum. En concreto la estructura de la imagen correspondería al ángulo NE. 